\title{
ENMD-I I 98, a novel tubulin-binding agent reduces HIF-I alpha and STAT3 activity in human hepatocellular carcinoma(HCC) cells, and inhibits growth and vascularization in vivo
}

\author{
Christian Moser $^{\dagger 1}$, Sven A Lang ${ }^{\dagger 1}$, Akira Mori ${ }^{1}$, Claus Hellerbrand ${ }^{2}$, \\ Hans J Schlitt ${ }^{1}$, Edward K Geissler ${ }^{1}$, William E Fogler ${ }^{3}$ and Oliver Stoeltzing*1
}

Address: ${ }^{1}$ Departments of Surgery and Surgical Oncology, Regensburg Medical Center, Regensburg, Germany, ${ }^{2}$ Department of Internal Medicine I; University of Regensburg Medical Center, Regensburg, Germany and ${ }^{3}$ EntreMed Inc., Rockville, MD, USA

Email: Christian Moser - christian.moser@klinik.uni-regensburg.de; Sven A Lang - sven.lang@klinik.uni-regensburg.de; Akira Mori - akr@kuhp.kyoto-u.ac.jp; Claus Hellerbrand - claus.hellerbrand@klinik.uni-regensburg.de; Hans J Schlitt - hans.schlitt@klinik.uniregensburg.de; Edward K Geissler - edward.geissler@klinik.uni-regensburg.de; William E Fogler - fogler@entremed.com;

Oliver Stoeltzing* - oliver.stoeltzing@klinik.uni-regensburg.de

* Corresponding author †Equal contributors

Published: 23 July 2008

BMC Cancer 2008, 8:206 doi:10.1186/147I-2407-8-206

This article is available from: http://www.biomedcentral.com/I47I-2407/8/206

(C) 2008 Moser et al; licensee BioMed Central Ltd.

This is an Open Access article distributed under the terms of the Creative Commons Attribution License (http://creativecommons.org/licenses/by/2.0), which permits unrestricted use, distribution, and reproduction in any medium, provided the original work is properly cited.

\begin{abstract}
Background: Hepatocellular carcinoma (HCC) represents a highly vascularized tumor entity and the process of angiogenesis is essential for the growth of HCC. Importantly, the pro-angiogenic transcription factors HIF-I $\alpha$ and STAT3 have been implicated in HCC progression, thus representing interesting targets for molecular targeted therapy. We hypothesized that therapeutic inhibition of HIF-I $\alpha$ could be achieved by using a novel tubulin-binding agent (ENMD-II98). ENMD-II98 is an analog of 2-methoxyestradiol (2ME2) with antiproliferative and antiangiogenic activity.
\end{abstract}

Methods: The human HCC cell lines HUH-7 and HepG2 were used for experiments. Effects of ENMD-II98 on constitutive and inducible (hypoxia, growth factors) activation of signaling cascades, including HIF-I $\alpha$ and STAT3, were investigated by Western blotting. Changes in VEGF expression were determined by real-time PCR. Effects of ENMD-I 198 on cancer cell migration and invasion were evaluated in in vitro-assays. The growth-inhibitory effects of ENMD-I $198(200 \mathrm{mg} / \mathrm{kg} /$ day) were determined in a subcutaneous tumor model (HUH-7).

Results: ENMD-I 198 inhibited the phosphorylation of MAPK/Erk, PI-3K/Akt and FAK. Moreover, activation of HIF-I $\alpha$ and STAT3 was dramatically reduced by ENMD-I 198, which resulted in lower VEGF mRNA expression $(P<0.05)$. In addition, tumor cell migratory and invasive properties were significantly inhibited ( $P<0.05$, for both). In vivo, treatment with ENMD-II 98 led to a significant reduction in tumor growth, tumor vascularization, and numbers of proliferating tumor cells $(\mathrm{P}<$ 0.05 for all).

Conclusion: The novel microtubule destabilizing agent ENMD-I 198 is suitable for inhibiting HIF$I \alpha$ and STAT3 in human HCC cells and leads to reduced tumor growth and vascularization in vivo. Hence, inhibition of HIF-I $\alpha$ and STAT3 could prove valuable for therapy of hepatocellular carcinoma. 


\section{Background}

Hepatocellular carcinoma (HCC) is the fifth most cancer worldwide, with a continuously increasing incidence [1]. Importantly, therapy of patients with HCC remains challenging, as this tumor entity is highly resistant to systemic therapies, and only few patients qualify for surgical or ablative strategies due to advanced tumor stage or limited liver function. In addition, the post-interventional relapse rates for HCC are high, thus overall demanding the development of novel, i.e. molecular targeted, treatment strategies for improving outcome of patients with HCC.

In general, HCC represents a hypervascularized tumor and its progression is closely related to angiogenesis $[2,3]$. Recent studies have not only identified the vascular endothelial growth factor (VEGF) to be overexpressed in hepatocellular carcinoma, but also that the transcription factor HIF- $1 \alpha$ plays a central role in HCC progression and angiogenesis [4-6]. Furthermore, the transcription factor signal transducer and activator of transcription 3 (STAT3), yet another inducer of angiogenesis in terms of up-regulating VEGF, is constitutively activated in HCC [7-9]. STAT3 has therefore drawn attention as a novel target for cancer therapy $[8,10-12]$. However, development of specific inhibitors to either HIF- $1 \alpha$, or STAT3 has proven difficult and research is ongoing. Nevertheless, certain compounds have lately been identified that exert an indirect anti-HIF-1 $\alpha$ activity, such as 2-methoxyestradiol (2ME2) [13]. 2ME2 has been demonstrated to impair activation of HIF- $1 \alpha$ through destabilization of microtubules, in addition to exhibiting antiproliferative and pro-apoptotic effects [13-15]. Moreover, 2ME2 has elicited growthinhibitory and antiangiogenic properties in preclinical models of cancer [13,15-21] and clinical trials evaluating 2ME2 have been conducted [22-24]. However, the suitability of microtubule destabilizing agents for targeting HIF-1 $\alpha$ in HCC has not been investigated to date.

The novel tubulin-binding compound ENMD-1198 (2methoxyestra-1, 3, 5, (10) 16-tetraene-3-carboxamide) is a new chemical entity based on a modified chemical structure of 2-methoxyestradiol, which has been designed to improve the pharmacokinetic properties, growth-inhibitory, and antiangiogenic properties of 2ME2 [25]. Preclinical studies identified ENMD-1198 as an orally active, microtubule disrupting agent that leads to arrest of cell division and apoptosis in tumor cells. Recently, ENMD1198 has entered a clinical phase I trial to evaluate the safety, tolerability, pharmacokinetics, and clinical benefit in patients with advanced cancer whose disease has failed to respond to existing therapies.

In the current study we hypothesized that ENMD-1198 could be used to inhibit HIF-1 $\alpha$ activation in human hepatocellular cancer cells, which would reduce tumor growth and angiogenesis in vivo. Importantly, since estrogen receptors (ER) are known to be present in advanced HCC, the therapeutic use of an estradiol-analogons, such as 2ME2, for antineoplastic/antiangiogenic therapy is unknown [26-28]. Thus far, randomized controlled trials comparing anti-estrogen therapy with conservative treatment were discouraging and showed neither an antitumoral nor any survival benefit $[27,29,30]$. Importantly, ENMD-1198 is devoid of such estrogenic effects and therefore could offer new perspectives for therapy [25]. We therefore sought to investigate, whether ENMD-1198 is efficacious for treatment of HCC, with a particular focus on its anti-HIF- $1 \alpha$ and antiangiogenic potential.

\section{Methods \\ Cells and culture conditions}

The human hepatocellular carcinoma cell lines HUH-7 and HepG2 were obtained from the American Type Culture Collection (ATCC, Manassas, VA). Cells were cultured in Dulbecco's modified Eagle's Medium (DMEM) or RPMI1640 (Gibco, Karlsruhe, Germany) supplemented with $10 \%$ fetal calf serum (FCS), and were maintained in $5 \% \mathrm{CO}_{2}$ at $37^{\circ} \mathrm{C}$. All in vitro experiments were done at $60 \%$ to $70 \%$ cell density. For in vivo experiments, trypsinized cells were resuspended in HBSS.

\section{Reagents and antibodies}

ENMD-1198 was provided by EntreMed, Inc. (Rockville, MD, USA) [25]. For in vitro experiments, ENMD-1198 was dissolved in DMSO $(0.1 \%)$ and equal concentrations of DMSO served as a control in all experiments. Antibodies against Akt, phosphorylated Aktser473, p44/42 MAPK1/2, phosphorylated p44/42 MAPK Thr202/Tyr204, signal transducer and activator of transcription 3 (STAT3), phosphorylated STAT3Tyr705, focal adhesion kinase (FAK) and phosphorylated FAKTyr925 were purchased from Cell Signaling Technologies (Beverly, MA). Anti-VEGF antibody was obtained from $R \& D$ Systems (Minneapolis, MN). Probing with an anti- $\beta$-actin antibody (Santa Cruz Biotechnology, Santa Cruz, CA) served as a loading control. Antibodies to HIF-1 $\alpha$ (NB100-105) were purchased from Novus Biologicals (Littleton, CO). Recombinant human EGF and HGF were used in stimulation assays (R\&D Systems).

\section{MTT analysis}

To evaluate cytotoxic effects of ENMD-1198 on tumor cells, HUH-7 and HepG2 cells were seeded into 96-well plates $\left(1 \times 10^{3} /\right.$ well; 12 wells per condition) and exposed to various concentrations of ENMD-1198 for 24 and 48 hours at $37^{\circ} \mathrm{C}$. We used the methylthiazole tetrazolium (MTT) assay to assess cell proliferation. 


\section{Immunoblot analysis of constitutive and inducible signaling} intermediates

To determine the effects of ENMD-1198 on signaling intermediates, cancer cells were incubated for 16 hours with FCS-RPMI containing ENMD-1198 (2,5 $\mu \mathrm{M})$, prior to stimulation with recombinant human EGF $(40 \mathrm{ng} / \mathrm{ml}$, $5 \mathrm{~min}$ and $10 \mathrm{~min} ; 1 \%$ FCS-RPMI). Whole cell lysates were prepared, as described elsewhere [31]. Protein samples $(75 \mu \mathrm{g})$ were subjected to Western blotting on a denaturating $10 \%$ SDS-PAGE. Analyses for HIF-1 $\alpha$ were performed on both nuclear protein extracts and whole cell lysates, as described [32]. In addition, tumor samples were subjected to Western blotting after lysis in RIPA-B buffer. [32,33]. Nuclear protein was extracted using a commercially available kit (NucBuster; Novagen, Merck Biosciences, Darmstadt, Germany). Experiments were performed in triplicates and confirmed in both cell lines (HUH-7, HepG2).

\section{Real-time PCR analyses}

For real-time PCR (RT-PCR), total RNA was isolated using Trizol Reagent (Invitrogen, Karlsruhe, Germany) and subsequently purified by ethanol precipitation. For each RNA sample, a $1 \mu \mathrm{g}$ aliquot was reversely transcribed into cDNA using the Superscript II Kit (Qiagen, Hilden, Germany). Primer pairs were as follows: VEGF165 (5'-GCACCCATGGCAGAAGGAGGAG; 3'AGCCCCCGCATCGCATCAG), and ATF3 (5'-CTGCAGAAAGAGTCGGAG; 3'-TGAGCCCGGACAATACAC). Primers were optimized for $\mathrm{MgCl} 2$ and annealing, and PCR products were confirmed by gel electrophoresis. RTPCR was performed using the LightCycler system and Roche Fast-Start Light Cycler-Master Hybridisation Probes master mix (Roche Diagnostics, Mannheim, Germany) [33]. Changes in VEGF-A expression were determined after 24 and 48 hours exposure to ENMD-1198 (2.5 $\mu \mathrm{M})$.

\section{Enzyme-linked immunosorbent assay for VEGF protein}

To determine changes in VEGF secretion by tumor cells, we used an ELISA kit specific to human VEGF-A (BioSource Europe, Nivelles, Belgium). HCC cells were plated at 40-50\% density and incubated \pm ENMD-1198 $(2.5 \mu \mathrm{M}$, 20 hours). Analyses of culture supernatants were performed according to the manufacturer's protocol.

\section{Migration and invasion assays}

To determine the effect of ENMD-1198 on cancer cell motility, migration assays were performed using modified Boyden chambers [32]. Briefly, $1 \times 10^{5}$ cells were resuspended in 1\% FCS-RPMI and seeded into inserts with 8 $\mu \mathrm{m}$ filter pores, which were either uncoated (migration assay), or matrigel-coated (invasion assay) (Becton Dickinson Bioscience, Heidelberg, Germany). 1\% FCS-DMEM \pm EGF $(40 \mathrm{ng} / \mathrm{ml})$, or HGF $(50 \mathrm{ng} / \mathrm{ml})$, served as a chemoattractant. After 48 hours, cells were fixed and stained
(Diff-Quick reagent, Dade Behring, Newark, NJ) and counted in four random fields.

\section{Animal models}

Eight-week-old male athymic nude mice (BALB/c nu/nu) (Charles River, Germany) were used for experiments, as approved by the Institutional Animal Care and Use Committee of the University of Regensburg and the regional authorities. In addition, experiments were conducted according to Guidelines for the Welfare of Animals in Experimental Neoplasia published by The United Kingdom Coordinating Committee on Cancer Research. The effects ENMD-1198 on the growth of human hepatocellular carcinoma cells were evaluated in a subcutaneous xenograft model. In brief, $1 \times 10^{6}$ human HCC cells (HUH-7) were injected into the subcutis of nude mice. After implantation, tumors were allowed to grow 7 days (volume $~ 100$ $\mathrm{mm}^{3}$ ) before treatment was initiated and mice randomized into one of two groups ( $n=10$ /group) receiving either vehicle or ENMD 1198 (200 mg/kg/day) per oral gavage. Tumor diameters were measured every other day, and tumor volumes were calculated (width ${ }^{2} \times$ length $\times$ $0.5)$.

\section{Immunohistochemical analyses of tumor vascularization and cancer cell proliferation}

Multiple cryo-sections and paraffin-embedded section were obtained from tumors for all immunohistochemical analyses. CD31-positive vessel area was assessed using rat anti-mouse CD31/PECAM-1 antibody (Pharmingen, San Diego, CA) and peroxidase-conjugated goat anti-rat IgG (Jackson Research Laboratories, West Grove, PA) on frozen sections, as previously described [32]. Antibody binding was visualized using stable diaminobenzidine. Images were obtained in four different quadrants of each tumor section ( $2 \mathrm{~mm}$ inside the tumor-normal tissue interface) at $40 \times$ magnification. Measurement of vessel area of CD31 stained vessels was performed by converting images to grayscale and setting a consistent threshold for all slides using ImageJ software (version 1.33; National Institute of Health, Bethesda, MD). Vessel areas were expressed as pixels per high-power field (HPF) [32]. To determine the amount of proliferating tumor cells, mice received intraperitoneal injections of BrdUrd (Sigma Aldrich, Germany) (1 mg/mouse) two hours prior to termination of animal studies. A commercially available BrdUrd-detection kit (Becton Dickinson) was used to visualize BrdUrduptake of cells in sections of tumors. Briefly, sections were incubated with anti-BrdUrd antibody solution, followed by streptavidin conjugated HRP-linked goat anti-mouse IgG2. Antibody binding was visualized by incubating slides in diaminobenzidine, with the aid of hematoxylin counterstaining. BrdUrd-positive tumor cells were counted in four fields per tumor section at $20 \times$ magnification and averages were calculated. 


\section{Statistical analysis}

Results of in vivo experiments were analyzed for significant outliers using the Grubb's test for detecting outliers http:/ /www.graphpad.com. Tumor-associated variables in in vivo experiments were tested for statistical significance using the Mann-Whitney U test for non-parametric data. The two-sided student's t-test was applied for analysis of in vitro data. All results are expressed as the mean \pm SEM.

\section{Results}

\section{Effects of ENMD-I 198 on growth of HCC cells in vitro}

To determine potential cytotoxic and anti-proliferative effects of ENMD-1198, the human hepatocellular carcinoma cell lines HUH-7 and HepG2 were exposed to ENMD-1198 at various concentrations (0-5 $\mathrm{mol} / \mathrm{L})$ and cell viability was determined by MTT analysis. Results show, that treatment with ENMD-1198 led to a significant dose-dependent inhibition of HCC cell growth in vitro (Fig. 1). The $\mathrm{IC}_{50}$ (24 hours) of ENMD-1198 was seen at $2.5 \mu \mathrm{mol} / \mathrm{L}$ (both cell lines) and this dose was used for all subsequent in vitro experiments. However, this $\mathrm{IC}_{50}$ appears to be higher compared to other cell cancer cell lines [25]. We conclude from these experiments that ENMD-1198 elicits anti-neoplastic activity on HCC cells, suggesting that this compound could be valuable for reducing growth of HCC in vivo.

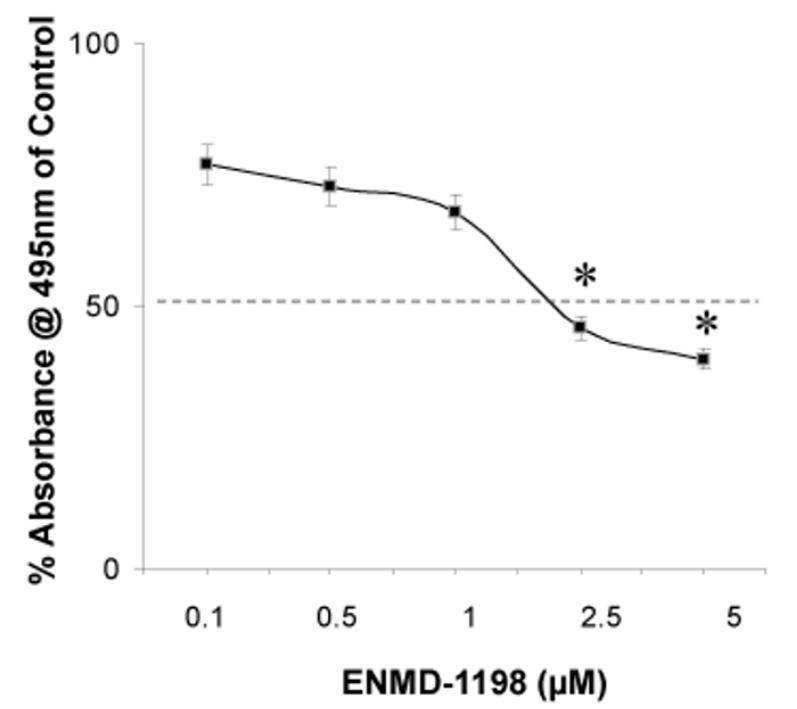

Figure I

Antiproliferative effects of ENMD- I 198 on HCC cells. $\mathrm{HUH}-7$ cells were incubated for $24 \mathrm{~h}$ with various concentrations of ENMD-I I 98 and MTT reading was performed thereafter. ENMD-I 198 dose-dependently elicited significant antiproliferative effects on $\mathrm{HCC}$ cells with an $\mathrm{IC}_{50}$ at $2.5 \mu \mathrm{M}$ in both cell lines (data shown for HUH-7) ( $* \mathrm{P}<0.05)$. Bars represent mean \pm SEM from three independent experiments. Bars: SEM.

\section{Effects of ENMD-I 198 on cell signaling and migration of HCC cells}

Since EGF is known to promote invasiveness and angiogenesis of HCC [34], we first investigated whether ENMD1198 could be used for interfering with activation of pathways involved in EGF-signaling in HCC cells. Treatment with ENMD-1198 substantially disrupted EGF signaling in terms of diminishing downstream phosphorylation of the substrates p44/42 MAPK and Akt (Fig. 2A). Moreover, the activation of STAT3, an important transcription factor for regulating VEGF-A in cancer cells, was markedly reduced by ENMD-1198 (Fig. 2A, B). In addition, an EGFinduced phosphorylation of FAK, yet another essential mediator for cancer cell invasiveness, was markedly inhibited by ENMD-1198 (Fig. 2A). As a functional consequence of multiple signaling pathway inhibition and interference with transcriptional regulation, ENMD-1198 significantly inhibited both EGF- and HGF-mediated cancer cell migration and invasiveness (Fig. 3A, B). These experiments suggest that ENMD-1198 may effectively interfere with crucial EGF-mediated and angiogenesisrelated signaling cascades in hepatocellular carcinoma cells. Hence, treatment with ENMD-1198 may not only

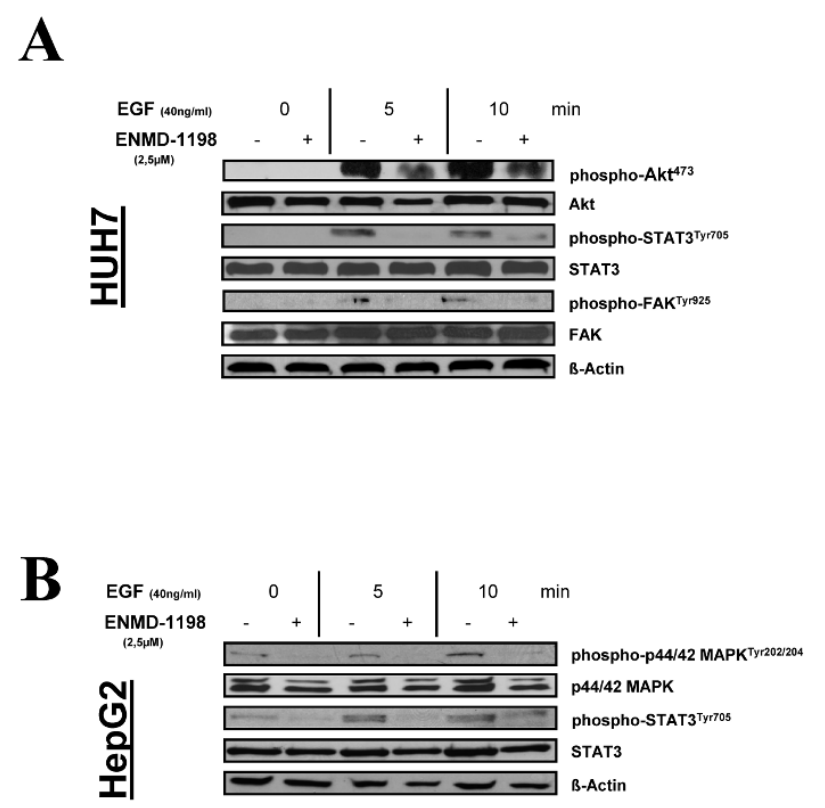

\section{Figure 2}

Effect of ENMD-I 198 on signaling in HCC cells. Western blot analysis was performed to determine signaling pathways affected by therapy with ENMD- I 198. Recombinant EGF $(40 \mathrm{ng} / \mathrm{ml})$ was used for stimulating cells after pre-incubation with ENMD-I 198 ( 16 hours). A) HUH-7 cells and B) HepG2 cells were used for experiments. ENMD- I 198 abrogated EGF-induced phosphorylation of Akt (HUH-7), FAK (HUH-7), p44/42 MAPK (HepG2), and STAT3 (HUH-7, HepG2). $\beta$-actin served as a loading control. 


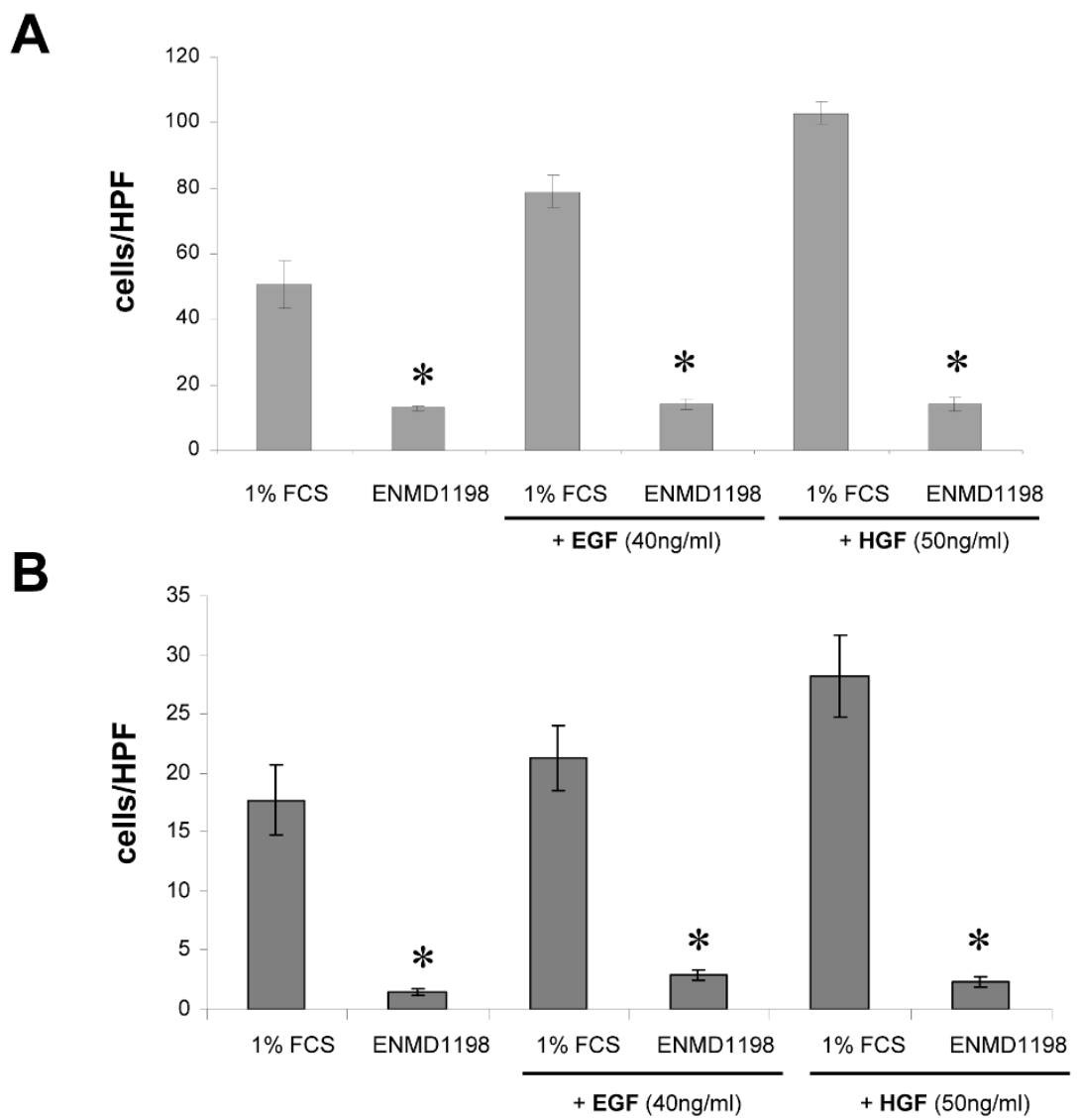

\section{Figure 3}

Impact of ENMD- I I 98 on cancer cell migration and invasion. The effects of ENMD-I I 98 on cancer cell migration were determined by using modified Boyden chambers. A) In migration assays (HUH-7), ENMD- I I 98 (2.5 $\mu$ M) effectively reduced cancer cell motility and blunted the response to either EGF, or HGF (*P < $0.0 \mathrm{I})$. B) The effects on cancer cell invasiveness were evaluated using Matrigel-coated inserts. ENMD-I 198 (2.5 $\mu \mathrm{M})$ significantly abrogated EGF- and HGF-mediated invasive properties of hepatocellular carcinoma cells, compared to controls (*P $<0.0$ I for all). Experiments were performed in triplicates and results were confirmed in a second cell line (HepG2). Bars: SEM.

affect tumor angiogenesis, but also harbors the potential to reduce metastasis through diminishing migratory and invasive properties of HCC cells.

\section{Effects of ENMD-I I98 on nuclear HIF-I $\alpha$ expression and VEGF expression}

The transcription factor HIF-1 $\alpha$ has been identified as an important promoter of HCC growth and angiogenesis [4,35]. Importantly, the ability of ENMD-1198 and 2ME2 to inhibit HIF-1 $\alpha$ has recently been suggested in preclinical tumor models of solid malignancies $[13,14]$. We therefore investigated whether ENMD-1198 could also interfere with hypoxia-induced signaling in human hepatocellular carcinoma cells. Western blotting showed that treatment with ENMD-1198 markedly diminished a hypoxia-induced $\left(1 \% \mathrm{O}_{2}\right)$ activation of HIF-1 $\alpha$ in cancer cells (Fig. 4A). As HIF-1 $\alpha$ is an important regulator of the pro-angiogenic molecule VEGF [36], we next determined the effects of ENMD-1198 on VEGF-A expression in HCC cells by real time PCR. Results show that treatment with ENMD-1198 slightly reduced constitutive (non-hypoxic) VEGF-A mRNA expression levels in HCC cells, though results were statistically significant (Fig. 4B). Similar modest effects of ENMD-1198 on VEGF protein were seen in an ELISA assay (Fig. 4C) and Western blot (Fig. 4D) under hypoxic conditions $\left(20 \mathrm{~h}, 1 \% \mathrm{O}_{2}\right)$ in vitro. However, HCC cells in general expressed only low levels of VEGF in in vitro conditions, suggesting that other angiogenic factors may also be involved in tumor angiogenesis of these tumor cells when growing in vivo. We conclude from these experiments that treatment with ENMD-1198 effectively 
A

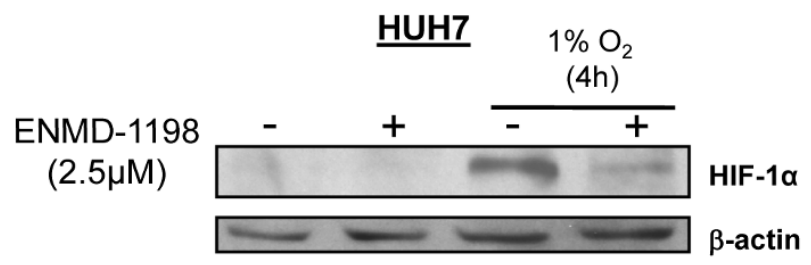

B
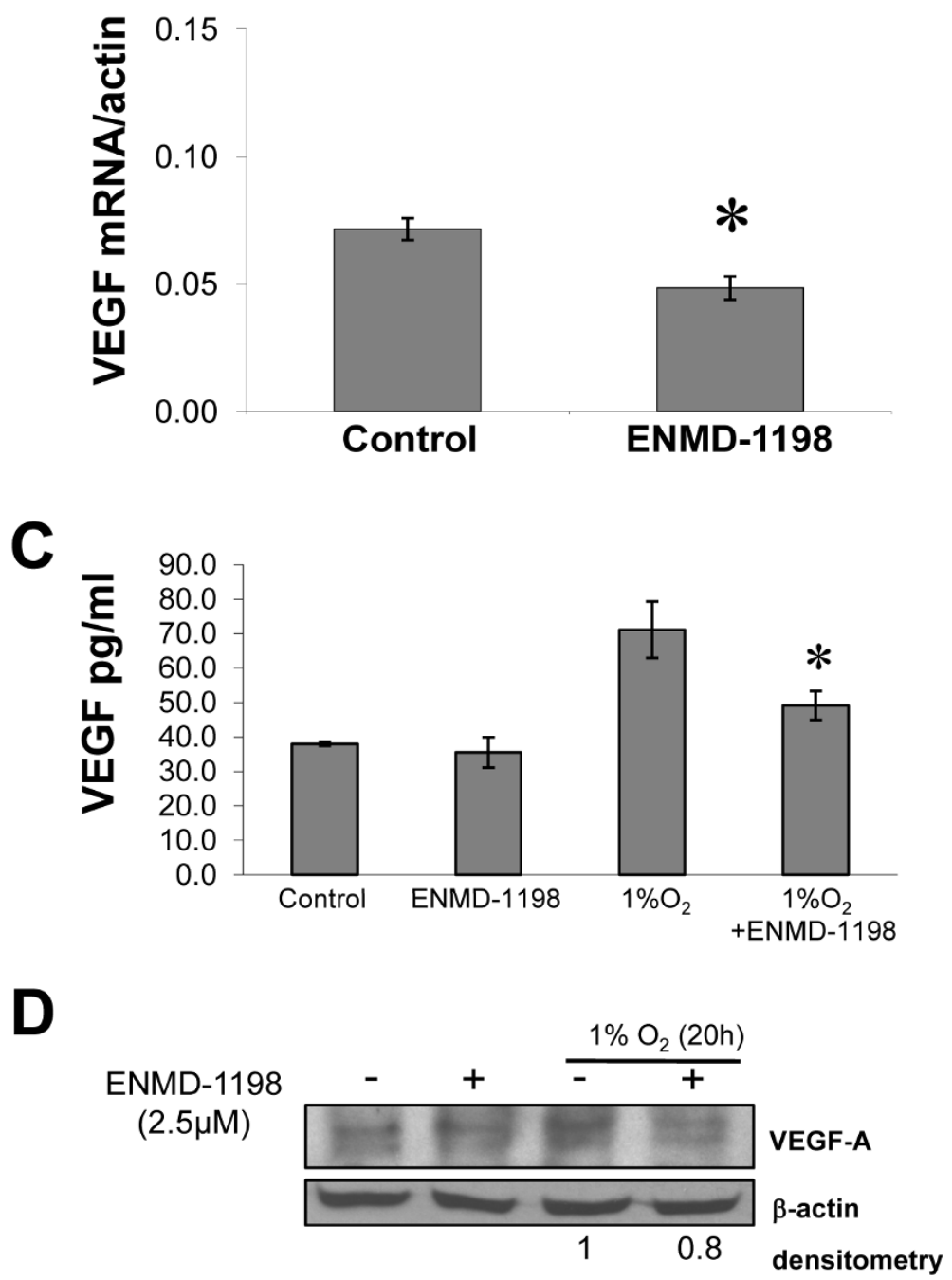

\section{Figure 4}

Effect of ENMD- I I 98 on HIF- I $\alpha$ and VEGF expression in HCC cells. To determine effects of ENMD- I I98 on nuclear HIF- I $\alpha$ expression, $\mathrm{HUH}-7$ cells were incubated for $16 \mathrm{~h} \pm$ ENMD- I 98 and subsequently exposed to hypoxia (I\% $\left.\mathrm{O}_{2}, 4 \mathrm{~h}\right)$. A) Western blot analysis of whole protein showed that ENMD-I 198 effectively blunted hypoxic induction of HIF-I $\alpha$ protein. B) In addition, treatment with ENMD-I 198 down-regulated constitutive VEGF-A mRNA levels in HCC cells (HepG2), as measured by real-time PCR (* $\mathrm{P}<0.0 \mathrm{I})$ ( $\mathrm{n}=3$ /group). VEGF-A mRNA expression is normalized to $\beta$-actin. C) ELISA analysis for VEGF in culture supernatants (HepG2). Hypoxia $\left(20 \mathrm{~h}, 1 \% \mathrm{O}_{2}\right)$ markedly increased VEGF protein. ENMD-I I 98 treatment lowered VEGF secretion under hypoxic conditions (*P $<0.05)$. D) Western blot analysis for VEGF. Cells were incubated under either non-hypoxic, or hypoxic conditions \pm ENMD- I 198. Treatment with ENMD-II98 slightly lowered the hypoxic induction of VEGF, as determined by densitometry. Bars: SEM. 
disrupts hypoxic signaling in HCC cells which is mediated through HIF- $1 \alpha$.

\section{Effects of ENMD-I 198 on growth and vascularization of hepatocellular carcinoma in vivo}

To estimate growth inhibitory and antiangiogenic effects of ENMD-1198 in vivo, we used a subcutaneous tumor model (HUH-7 cells). Treatment with ENMD-1198 (200 $\mathrm{mg} / \mathrm{kg} /$ day) significantly reduced growth of HUH-7 tumors, compared to controls (Fig. 5A). This reduction in tumor growth was also reflected by final tumor weights of excised tumors on day 19, which were significantly lower in the ENMD-1198 treatment group (Fig. 5B). Importantly, mouse body weights did statistically not differ among these two groups (controls: $22.1 \pm 0.7$; ENMD1198: $20.3 \pm 0.9$ [mean $\pm \mathrm{SEM}] ; \mathrm{P}=0.15)$. Furthermore, vascularization of HUH-7 tumors in terms of CD31-posi- tive vessel area was significantly reduced in tumor sections of the ENMD-1198 group (Fig. 6A). Moreover, treatment with ENMD-1198 also reduced the number of proliferating (BrdUrd-positive) tumor cells (Fig. 6B). Importantly, Western blotting of tumor tissues showed markedly decreased HIF-1 $\alpha$ expression in ENMD-1198 treated tumors, suggesting that this target is inhibited in vivo (Fig. 6C). In conclusion, these experiments demonstrate that ENMD-1198 effectively inhibits growth of hepatocellular carcinoma through direct effects on the tumor cells, and also through inhibition of angiogenesis.

\section{Discussion}

The present study shows that the 2ME2-analog ENMD1198 interferes with growth factor-induced signaling in hepatocellular carcinoma and effectively inhibits HIF-1 $\alpha$ and STAT3 activation. This disruption in cell signaling

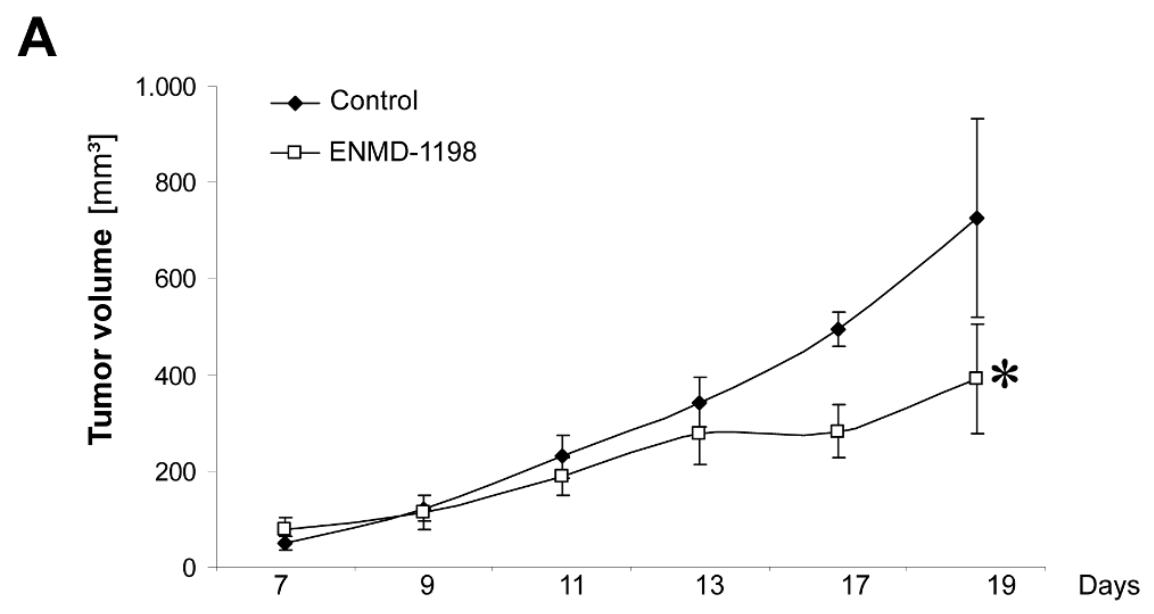

B

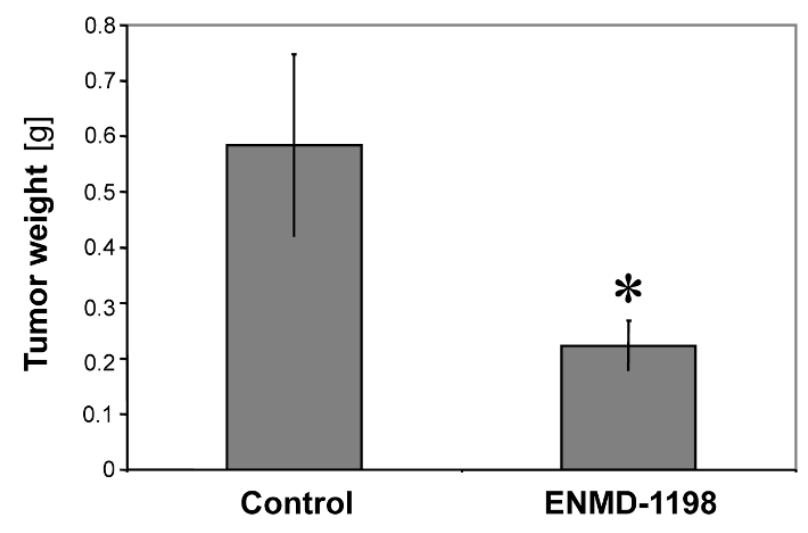

\section{Figure 5}

Effect of ENMD- I 198 on growth of colorectal cancer cells in vivo. To determine growth-inhibitory effects of ENMDI I 98 in vivo, HUH-7 cells were implanted subcutaneously into mice ( $\mathrm{n}=10 /$ group) which received either ENMD- I I 98 (200 mg/ $\mathrm{kg} /$ day) or diluent when tumors became palpable. A) Treatment with ENMD-I 198 led to a significant growth inhibition of xenografted hepatocellular tumors, compared to controls (*P < 0.05). B) Final tumor weights (day I9) in the ENMD- II98 treatment group were significantly lower, compared to excised tumors of the control group (*P < 0.05). Bars: mean \pm SEM. 

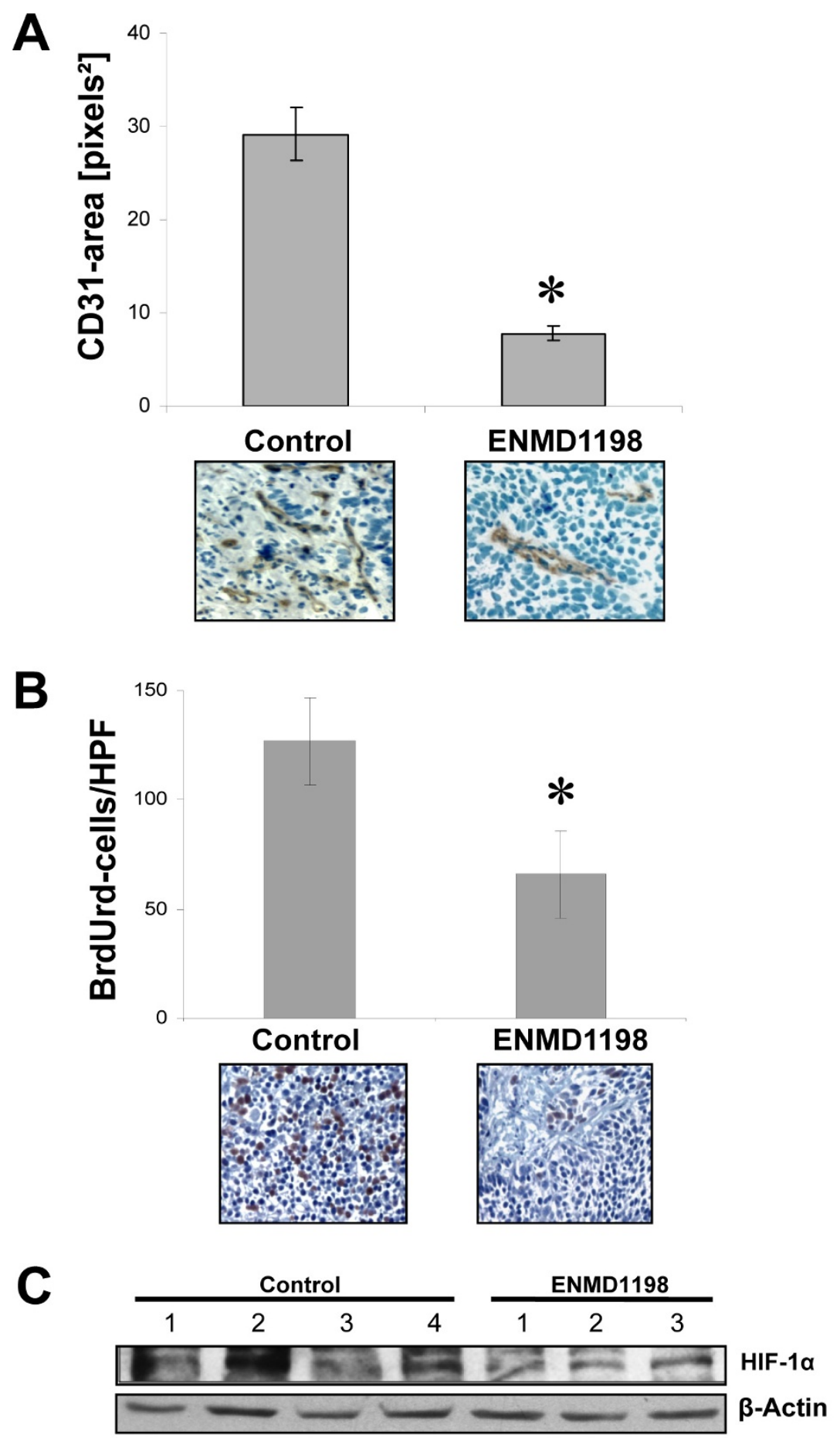

\section{Figure 6}

Effect of ENMD-I 198 on tumor vascularization and tumor cell proliferation. A) Immunohistochemical analysis of tumor vascularization (CD3I-positive vessels). Densitometric analysis of images from CD3I-stained tissue sections from all tumors showed that vessel area was significantly reduced in ENMD- I I 98 -treated tumors (*P < 0.0 I). B) ENMD-I I 98 significantly decreased the number of proliferating (BrdUrd-positive) tumor cells in tissue sections $(* \mathrm{P}<0.0 \mathrm{I})$. For both vessel area and cell proliferation, representative images are illustrated. Results shown are the mean \pm SEM. C) Western blot analysis for HIF-I $\alpha$ expression in HCC tumors showed a substantial reduction of HIF-I $\alpha$ in ENMD-I I 98 treated tumors. 
leads to a significant reduction of migratory and invasive properties of cancer cells and diminishes VEGF mRNA expression.

Tissue hypoxia constitutes as one of the main characteristics of the tumor microenvironment and has been shown to be implicated in the progression and metastasis of various solid malignancies [37-39]. One key regulatory protein in the cell response to changing oxygen levels is the hypoxia inducible factor- $1 \alpha$ (HIF-1 $\alpha$ ). Interestingly, HIF$1 \alpha$ activation appears to be a very early event in carcinogenesis and this protein is expressed before histological evidence of angiogenesis or invasion even occur [40]. In regards to HCC, overexpression of HIF- $1 \alpha$ has been reported, which has been associated with a poor prognosis [41-43]. Recently, both HIF-1 $\alpha$ and VEGF were identified to be involved in the malignant transformation of dysplastic liver nodules and additionally a hypoxia-independent overexpression of HIF- $1 \alpha$ has been shown to be involved in a model of mouse hepatocarcinogenesis $[4,35]$. Overall, these studies suggest that anti-HIF- $1 \alpha$ therapy could prove valuable for treatment of HCC, or its pre-malignant lesions. However, specific inhibitors to HIF- $1 \alpha$ are still under development, thus demanding the evaluation of alternative strategies for inhibiting HIF- $1 \alpha$ in cancers. Interestingly, recent studies have demonstrated that 2ME2, an endogenous metabolite of estrogen, elicits antineoplastic efficacy which in part is mediated by an anti-HIF-1 $\alpha$ activity $[13,14]$. The substance used in our study, ENMD-1198, is based on a modified chemical structure of 2ME2. However, ENMD-1198 has previously been evaluated in models of HCC. Indeed, we now demonstrate that ENMD-1198 effectively inhibits activation of HIF- $1 \alpha$ in HCC, ultimately leading to a reduction of tumor growth and vascularization in vivo. However, the exact mechanism by which 2ME2 and ENMD-1198 inhibit HIF- $1 \alpha$ is not fully understood. Recent studies suggested that $2 \mathrm{ME} 2$ treatment induces superoxide radicals in tumors [44,45], which in turn could down-regulate HIF$1 \alpha$. Another potential mechanism for reducing HIF-1 $\alpha$ activity could be mediated through interference with STAT3 phosphorylation, as STAT3 is required for forming an active HIF-1 complex [46]. In HCC, STAT3 appears to play a central role, as this transcription factor is implicated in oncogenesis and metastasis [7,9,12]. Furthermore, STAT3 appears to be necessary for a PI-3K/Akt-mediated hypoxia-independent HIF- $1 \alpha$ protein synthesis $[46,47]$. Importantly, our results indicate that ENMD-1198 effectively diminishes phosphorylation of STAT3 in HCC cells, a finding which has not been reported for $2 \mathrm{ME} 2 \mathrm{com}-$ pounds to date. Hence, we now provide evidence for another mechanism for impairing HIF- $1 \alpha$ function in cancer cells by 2ME2-like inhibitors in terms of diminishing STAT3 activation. Moreover, ENMD-1198 also reduced phosphorylation of Akt, a signaling intermediate that is up-stream of HIF- $1 \alpha$, thus resulting in further impairment of HIF- $1 \alpha$ activity. This was also reflected in Western blot results for HIF-1 $\alpha$ expression analysis in tumor tissues, which were markedly reduced in the ENMD-1198 treated tumors. In fact, one has to realize that tumor sizes differ significantly among these treatment groups, which per se could affect HIF- $1 \alpha$ expression. Nevertheless, we also detected a diminished STAT3 activation by Western blotting of tumor tissues in the ENMD1198 treatment group (data not shown), suggesting that the drug also effectively inhibits both targets in vivo.

Another important aspect is the observed anti-metastatic property of ENMD-1198 in vitro, as treatment of HCC cells led to reduced phosphorylation of the pro-migratory signaling component FAK. In in vitro assays, ENMD-1198 substantially abrogated EGF- and HGF-mediated cancer cell migration and invasiveness, suggesting that this substance could be valuable for reducing HCC metastasis. Development of intra-hepatic metastases is a common problem in HCC patients who underwent liver resection for HCC, or are on the waiting list for transplantation. Since HIF- $1 \alpha$ and STAT3 both promote metastasis formation, treatment with ENMD-1198 appears to be reasonable and warrants further investigation. ENMD-1198 is already being investigated in a phase I trial in advanced cancers and results from these trials will be important for further defining the suitability of this agent in cancer therapy.

\section{Conclusion}

In conclusion, our study demonstrates that treatment with ENMD-1198 harbors significant potential for reducing growth and vascularization of hepatocellular carcinoma. Importantly, ENMD-1198 effectively diminishes both HIF- $1 \alpha$ and STAT3 activation in HCC cells, which represent important mediators of HCC progression. Our data are therefore in favor of evaluating this concept of targeting microtubules in clinical trials for therapy of human hepatocellular carcinoma.

\section{Competing interests}

The authors CM, SAL, AM, CH, HJS, EKG and OS have no competing interest to declare. The co-author WEF is employee at EntreMed Inc., Rockville MD.

\section{Authors' contributions}

The authors CM and SAL performed the in vitro and in vivo experiments, analyzed the data and prepared the manuscript, AM performed staining procedures, $\mathrm{CH}$ assisted in experimental design and manuscript review, HJS and EKG edited and reviewed the manuscript, WEF provided the substance, technical information and reviewed the manuscript, OS is principal investigator, designed the experimental outlines, aided in manuscript preparation, 
reviewed and revised the manuscript. All authors read and approved the final manuscript

\section{Acknowledgements}

These studies were supported in part by the German Cancer Aid (Deutsche Krebshilfe, Max-Eder Nachwuchsgruppen-Programm, Bonn, Germany) (to O.S.), and a grant from the University of Regensburg, Medical Faculty (ReForM) (O.S.; S.A.L.). The authors thank Christine Wagner and Kathrin Stengel for excellent technical assistance.

\section{References}

I. Llovet JM: Updated treatment approach to hepatocellular carcinoma. J Gastroenterol 2005, 40(3):225-235.

2. Kuboki S, Shimizu H, Mitsuhashi N, Kusashio K, Kimura F, Yoshidome H, Ohtsuka M, Kato A, Yoshitomi H, Miyazaki M: Angiopoietin-2 levels in the hepatic vein as a useful predictor of tumor invasiveness and prognosis in human hepatocellular carcinoma. J Gastroenterol Hepatol 2007.

3. Pang R, Poon RT: Angiogenesis and antiangiogenic therapy in hepatocellular carcinoma. Cancer Lett 2006, 242(2): 15 I-I67.

4. Nakamura K, Zen Y, Sato Y, Kozaka K, Matsui O, Harada K, Nakanuma $Y$ : Vascular endothelial growth factor, its receptor Flk$I$, and hypoxia inducible factor-I alpha are involved in malignant transformation in dysplastic nodules of the liver. Hum Pathol 2007, 38(10): 1532-1546.

5. Torimura T, Sata M, Ueno T, Kin M, Tsuji R, Suzaku K, Hashimoto O, Sugawara $\mathrm{H}$, Tanikawa $\mathrm{K}$ : Increased expression of vascular endothelial growth factor is associated with tumor progression in hepatocellular carcinoma. Hum Pathol 1998, 29(9):986-991.

6. Wu XZ, Xie GR, Chen D: Hypoxia and hepatocellular carcinoma: The therapeutic target for hepatocellular carcinoma. J Gastroenterol Hepatol 2007, 22(8): I I78- I 82.

7. Lau CK, Yang ZF, Lam SP, Lam CT, Ngai P, Tam KH, Poon RT, Fan ST: Inhibition of Stat 3 activity by YC-I enhances chemo-sensitivity in hepatocellular carcinoma. Cancer Biol Ther 2007, 6(12):

8. Li WC, Ye SL, Sun RX, Liu YK, Tang ZY, Kim Y, Karras JG, Zhang H: Inhibition of growth and metastasis of human hepatocellular carcinoma by antisense oligonucleotide targeting signal transducer and activator of transcription 3. Clin Cancer Res 2006, I 2(23):7|40-7| 48.

9. Yang SF, Wang SN, Wu CF, Yeh YT, Chai CY, Chunag SC, Sheen MC, Lee KT: Altered p-STAT3 (tyr705) expression is associated with histological grading and intratumour microvessel density in hepatocellular carcinoma. J Clin Pathol 2007, 60(6):642-648.

10. Buettner R, Mora LB, Jove R: Activated STAT signaling in human tumors provides novel molecular targets for therapeutic intervention. Clin Cancer Res 2002, 8(4):945-954.

II. Fuke $H$, Shiraki K, Sugimoto K, Tanaka J, Beppu T, Yoneda K, Yamamoto N, Ito K, Masuya M, Takei Y: Jak inhibitor induces $\mathbf{S}$ phase cell-cycle arrest and augments TRAIL-induced apoptosis in human hepatocellular carcinoma cells. Biochem Biophys Res Commun 2007, 363(3):738-744.

12. Niu G, Wright KL, Huang M, Song L, Haura E, Turkson J, Zhang S, Wang T, Sinibaldi D, Coppola D, Heller R, Ellis LM, Karras J, Bromberg J, Pardoll D, Jove R, Yu H: Constitutive Stat3 activity up-regulates VEGF expression and tumor angiogenesis. Oncogene 2002, 2 I ( I 3):2000-2008.

13. Mabjeesh NJ, Escuin D, LaVallee TM, Pribluda VS, Swartz GM, Johnson MS, Willard MT, Zhong H, Simons JW, Giannakakou P: 2ME2 inhibits tumor growth and angiogenesis by disrupting microtubules and dysregulating HIF. Cancer Cell 2003, 3(4):363-375.

14. Ricker JL, Chen Z, Yang XP, Pribluda VS, Swartz GM, Van Waes C: 2methoxyestradiol inhibits hypoxia-inducible factor Ialpha, tumor growth, and angiogenesis and augments paclitaxel efficacy in head and neck squamous cell carcinoma. Clin Cancer Res 2004, I 0(24):8665-8673.

15. Chauhan D, Catley L, Hideshima T, Li G, Leblanc R, Gupta D, Sattler M, Richardson P, Schlossman RL, Podar K, Weller E, Munshi N, Anderson KC: 2-Methoxyestradiol overcomes drug resistance in multiple myeloma cells. Blood 2002, 100(6):2187-2194.
16. Dingli D, Timm M, Russell SJ, Witzig TE, Rajkumar SV: Promising preclinical activity of 2-methoxyestradiol in multiple myeloma. Clin Cancer Res 2002, 8( I 2):3948-3954.

17. Fotsis T, Zhang Y, Pepper MS, Adlercreutz H, Montesano R, Nawroth PP, Schweigerer L: The endogenous oestrogen metabolite 2methoxyoestradiol inhibits angiogenesis and suppresses tumour growth. Nature 1994, 368(6468):237-239.

18. Huober JB, Nakamura S, Meyn R, Roth JA, Mukhopadhyay T: Oral administration of an estrogen metabolite-induced potentiation of radiation antitumor effects in presence of wild-type p53 in non-small-cell lung cancer. Int J Radiat Oncol Biol Phys 2000, 48(4): I I27-I I 37

19. Klauber N, Parangi S, Flynn E, Hamel E, D'Amato RJ: Inhibition of angiogenesis and breast cancer in mice by the microtubule inhibitors 2-methoxyestradiol and taxol. Cancer Res 1997, $57(1): 81-86$

20. Schumacher G, Neuhaus $P$ : The physiological estrogen metabolite 2-methoxyestradiol reduces tumor growth and induces apoptosis in human solid tumors. J Cancer Res Clin Oncol 200I, I 27(7):405-410.

2I. Kang SH, Cho HT, Devi S, Zhang Z, Escuin D, Liang Z, Mao H, Brat DJ, Olson JJ, Simons JW, Lavallee TM, Giannakakou P, Van Meir EG, Shim H: Antitumor effect of 2-methoxyestradiol in a rat orthotopic brain tumor model. Cancer Res 2006, 66(24): II99I-II997.

22. James J, Murry DJ, Treston AM, Storniolo AM, Sledge GW, Sidor C Miller KD: Phase I safety, pharmacokinetic and pharmacodynamic studies of 2-methoxyestradiol alone or in combination with docetaxel in patients with locally recurrent or metastatic breast cancer. Invest New Drugs 2007, 25(I):4I-48.

23. Sweeney C, Liu G, Yiannoutsos C, Kolesar J, Horvath D, Staab MJ, Fife K, Armstrong V, Treston A, Sidor C, Wilding G: A phase II multicenter, randomized, double-blind, safety trial assessing the pharmacokinetics, pharmacodynamics, and efficacy of oral 2-methoxyestradiol capsules in hormone-refractory prostate cancer. Clin Cancer Res 2005, I I ( 18):6625-6633.

24. Mueck $A O$, Seeger $H$, Wallwiener D, Huober J: Is the combination with 2-methoxyestradiol able to reduce the dosages of chemotherapeutices in the treatment of human ovarian cancer? Preliminary in vitro investigations. Eur J Gynaecol Oncol 2004, 25(6):699-70I.

25. Lavallee TM, Burke PA, Swartz GM, Hamel E, Agoston GE, Shah J, Suwandi L, Hanson AD, Fogler WE, Sidor CF, Treston AM: Significant antitumor activity in vivo following treatment with the microtubule agent ENMD-II98. Mol Cancer Ther 2008, 7(6): I472-I 482.

26. lavarone M, Lampertico P, Seletti C, Francesca Donato M, Ronchi G, del Ninno E, Colombo M: The clinical and pathogenetic significance of estrogen receptor-beta expression in chronic liver diseases and liver carcinoma. Cancer 2003, 98(3):529-534.

27. Liu CL, Fan ST, Ng IO, Lo CM, Poon RT, Wong J: Treatment of advanced hepatocellular carcinoma with tamoxifen and the correlation with expression of hormone receptors: a prospective randomized study. Am J Gastroenterol 2000, 95(I):218-222.

28. Villa E, Camellini L, Dugani A, Zucchi F, Grottola A, Merighi A, Buttafoco $P$, Losi L, Manenti F: Variant estrogen receptor messenger RNA species detected in human primary hepatocellular carcinoma. Cancer Res 1995, 55(3):498-500.

29. Chow PK, Tai BC, Tan CK, Machin D, Win KM, Johnson PJ, Soo KC: High-dose tamoxifen in the treatment of inoperable hepatocellular carcinoma: A multicenter randomized controlled trial. Hepatology 2002, 36(5): I22I-I226.

30. Perrone F, Gallo C, Daniele B, Gaeta GB, Izzo F, Capuano G, Adinolfi LE, Mazzanti R, Farinati F, Elba S, Piai G, Calandra M, Stanzione M, Mattera D, Aiello A, De Sio I, Castiglione F, Russo M, Persico M, Felder M, Manghisi OG, De Maio E, Di Maio M, Pignata S: Tamoxifen in the treatment of hepatocellular carcinoma: 5-year results of the CLIP-I multicentre randomised controlled trial. Curr Pharm Des 2002, 8(II): I0I3-10I9.

31. Stoeltzing O, Liu W, Reinmuth N, Fan F, Parikh AA, Bucana CD, Evans $D B$, Semenza GL, Ellis LM: Regulation of hypoxia-inducible factor-Ialpha, vascular endothelial growth factor, and angiogenesis by an insulin-like growth factor-I receptor autocrine loop in human pancreatic cancer. Am J Pathol 2003, 163(3): $1001-1011$. 
32. Lang SA, Klein D, Moser C, Gaumann A, Glockzin G, Dahlke MH, Dietmaier W, Bolder U, Schlitt HJ, Geissler EK, Stoeltzing O: Inhibition of heat shock protein $\mathbf{9 0}$ impairs epidermal growth factor-mediated signaling in gastric cancer cells and reduces tumor growth and vascularization in vivo. Mol Cancer Ther 2007, 6(3): I I23-II 32.

33. Lang SA, Moser C, Gaumann A, Klein D, Glockzin G, Popp FC, Dahlke $\mathrm{MH}$, Piso P, Schlitt HJ, Geissler EK, Stoeltzing O: Targeting heat shock protein 90 in pancreatic cancer impairs insulin-like growth factor-I receptor signaling, disrupts an interleukin-6/ signal-transducer and activator of transcription 3/hypoxiainducible factor- I alpha\} autocrine loop, and reduces orthotopic tumor growth. Clin Cancer Res 2007, I3(2I):6459-6468.

34. Fukui $K$, Tamura $S$, Wada $A$, Kamada $Y$, Igura $T$, Kiso $S$, Hayashi $N$ : Expression of Rab5a in hepatocellular carcinoma: Possible involvement in epidermal growth factor signaling. Hepatol Res 2007, 37(II):957-965.

35. Tanaka H, Yamamoto M, Hashimoto N, Miyakoshi M, Tamakawa S, Yoshie M, Tokusashi Y, Yokoyama K, Yaginuma Y, Ogawa K: Hypoxia-independent overexpression of hypoxia-inducible factor I alpha as an early change in mouse hepatocarcinogenesis. Cancer Res 2006, 66(23): I I 263-II 1270.

36. Forsythe JA, liang BH, lyer NV, Agani F, Leung SW, Koos RD, Semenza GL: Activation of vascular endothelial growth factor gene transcription by hypoxia-inducible factor I. Mol Cell Biol 1996, I6(9):4604-46/3.

37. Dachs GU, Tozer GM: Hypoxia modulated gene expression: angiogenesis, metastasis and therapeutic exploitation. Eur J Cancer 2000, 36(1 3 Spec No): $1649-1660$.

38. Sutherland RM: Tumor hypoxia and gene expression--implications for malignant progression and therapy. Acta Oncol 1998 , 37(6):567-574.

39. Wykoff CC, Beasley NJ, Watson PH, Turner KJ, Pastorek J, Sibtain A, Wilson GD, Turley H, Talks KL, Maxwell PH, Pugh CW, Ratcliffe PJ, Harris AL: Hypoxia-inducible expression of tumor-associated carbonic anhydrases. Cancer Res 2000, 60(24):7075-7083.

40. Zhong H, De Marzo AM, Laughner E, Lim M, Hilton DA, Zagzag D, Buechler P, Isaacs WB, Semenza GL, Simons JW: Overexpression of hypoxia-inducible factor Ialpha in common human cancers and their metastases. Cancer Res 1999, 59(22):5830-5835.

4I. Birner P, Schindl M, Obermair A, Plank C, Breitenecker G, Oberhuber G: Overexpression of hypoxia-inducible factor I alpha is a marker for an unfavorable prognosis in early-stage invasive cervical cancer. Cancer Res 2000, 60( I 7):4693-4696.

42. Matsuyama T, Nakanishi K, Hayashi T, Yoshizumi $Y$, Aiko S, Sugiura Y, Tanimoto T, Uenoyama M, Ozeki Y, Maehara T: Expression of hypoxia-inducible factor-Ialpha in esophageal squamous cell carcinoma. Cancer Sci 2005, 96(3): I76- | 82.

43. Yasuda S, Arii S, Mori A, Isobe N, Yang W, Oe H, Fujimoto A, Yonenaga $Y$, Sakashita $H$, Imamura M: Hexokinase II and VEGF expression in liver tumors: correlation with hypoxia-inducible factor I alpha and its significance. J Hepatol 2004, 40(I): II $17-123$.

44. Salceda S, Caro J: Hypoxia-inducible factor I alpha (HIF-I alpha) protein is rapidly degraded by the ubiquitin-proteasome system under normoxic conditions. Its stabilization by hypoxia depends on redox-induced changes. J Biol Chem 1997, 272(36):22642-22647.

45. Srinivas $V$, Zhu X, Salceda S, Nakamura R, Caro J: Hypoxia-inducible factor Ialpha (HIF-Ialpha) is a non-heme iron protein. Implications for oxygen sensing. J Biol Chem 1998, 273(29): 18019-18022.

46. Xu Q, Briggs J, Park S, Niu G, Kortylewski M, Zhang S, Gritsko T, Turkson J, Kay H, Semenza GL, Cheng JQ, Jove R, Yu H: Targeting Stat3 blocks both HIF-I and VEGF expression induced by multiple oncogenic growth signaling pathways. Oncogene 2005, 24(36):5552-5560.

47. Semenza GL: Targeting HIF-I for cancer therapy. Nat Rev Cancer 2003, 3(10):72।-732.

\section{Pre-publication history}

The pre-publication history for this paper can be accessed here: http://www.biomedcentral.com/1471-2407/8/206/pre pub
Publish with Bio Med Central and every scientist can read your work free of charge

"BioMed Central will be the most significant development for disseminating the results of biomedical research in our lifetime. "

Sir Paul Nurse, Cancer Research UK

Your research papers will be:

- available free of charge to the entire biomedical community

- peer reviewed and published immediately upon acceptance

- cited in PubMed and archived on PubMed Central

- yours - you keep the copyright
BiolMedcentral 